\title{
Note
}

[Agr. Biol. Chem., Vol. 33, No. 6, p. 962 964, 1969]

\section{Metabolism of Hydrocarbons in Microorganisms}

\author{
Part II. Degradation of Toluene by Cell-Free Extracts \\ of Pseudomonas mildenbergii \\ By Junichiro Nozaka and Masamichi Kusunose \\ Research Laboratory of Biochemistry, Toneyama Hospital, National Sonatorium, \\ Toyonaka, Osaka, and Toneyama Institute for Tuberculosis Research, \\ Osaka City University Medical School, Toyonaka, Osaka \\ Received October 23, 1968
}

In a previous paper, we reported that cellfree extracts obtained from Pseudomonas aeruginosa grown on xylene as a sole carbon source converted $p$-xylene-methyl $-{ }^{14} \mathrm{C}$ and toluenemethyl ${ }^{14} \mathrm{C}$ to $p$-toluic and benzoic acids, respectively, by way of the corresponding alcohols." This finding supports the pathway of toluene degradation via benzoic acid first proposed by Kitagawa. ${ }^{2 !}$ The enzyme system responsible for the first step of this pathway was demonstrated to be very similar to that of the alkane hydroxylation previously described in the requirement for multiple proteins and cofactors. ${ }^{31}$ The present communication represents some properties of cell-free extracts obtained from other toluene-utilizing $P_{\text {seudo- }}$ monas species isolated in this laboratory. This organism appears to attack toluene through the cleavage of benzene ring, in agreement with the pathway of toluene degradation postulated by Claus and Walker."

A toluene-utilizing organism was isolated from sewage by enrichment culture technique.

1) J. Nozaka ann M. Kusunose, Agr. Biol. Chem., 32, 1033 (1968).

2) M. Kitagawa, J. Biochem., 43, 553 (1956).

3) M. Kusunose, K. Ichihara, E. Kusunose, J. Nozaka and J. Matsumoto, Agr. Biol. Chem., 31, 990 (1967).

4) D. Claus and N. Walker, J. Gen. Micrabiol., 36, 107 (1964).
The organism was a gram-negative rod, 0.3 to 0.5 by 1.0 to 2.5 microns, occurring singly, and was motile with a polar flagellum. Colonies on nutrient agar were small, circular, entire, convex and yellowish. Growth in nutrient broth became turbid with slimy sediment and with no pellicle. Gelatine was not liquefied. Litmus milk became alkaline and was not peptonized. Starch was not hydrolyzed. Indol was not produced. Nitrate was not reduced to nitrite and nitrogen gas. Growth on agar stroke was moderate, fluorescent, and filiform. Hydrogen sulfide was not produced. Growth was excellent at $25 \sim 30^{\circ} \mathrm{C}$, but poor at $37^{\circ} \mathrm{C}$. Based on these observations, the organism was tentatively identified as Pseudomonas mildenbergii. ${ }^{51}$

The organism was grown in the medium containing mineral salts as described before, ${ }^{11}$ with toluene as the sole carbon source for 48 hr at $30^{\circ} \mathrm{C}$. The cell-paste was suspended in four parts of $0.02 \mathrm{~m}$ Tris- $\mathrm{HCl}$ buffer, $\mathrm{pH} 8.0$, and treated with a Branson S-125 Sonifier for $5 \mathrm{~min}$, followed by centrifugation at 100,000 $\times g$ for $30 \mathrm{~min}$. The crude extracts thus obtained was stored in frozen-state. The reaction mixture $(1 \mathrm{ml})$ containing the crude

5) "Bergey's Manual of Determinative Bacteriology", The Williams and Wilkins Co., 1957. 
extracts (6 $\mathrm{mg}$ of proteins), $9 \mathrm{~m} \mu$ moles of toluene-methyl $-{ }^{14} \mathrm{C}\left(2.15 \times 10^{5} \mathrm{cpm}\right), 100 \mu$ moles of Tris-HCl buffer, $\mathrm{pH} 7.6$, and $0.25 \mu \mathrm{mole}$ of NADPH was incubated at $30^{\circ} \mathrm{C}$ for $30 \mathrm{~min}$. The reaction was stopped by the addition of $0.4 \mathrm{ml}$ of $20 \% \mathrm{H}_{2} \mathrm{SO}_{4}$, then the reaction mixture was extracted twice with $5 \mathrm{ml}$ of ether. A small amount of alkali was added to the ether extracts, which was subsequently evaporated to dryness. The residue was mixed with authentic organic acids, and submitted to chromatography on Celite column. As shown in Fig. 1, a major radioactive peak coincided with the titration peak of authentic acetic acid, while a minor radioactive peak, with that of authentic benzoic acid. In addition, thin-layer chromatography of the concentrated

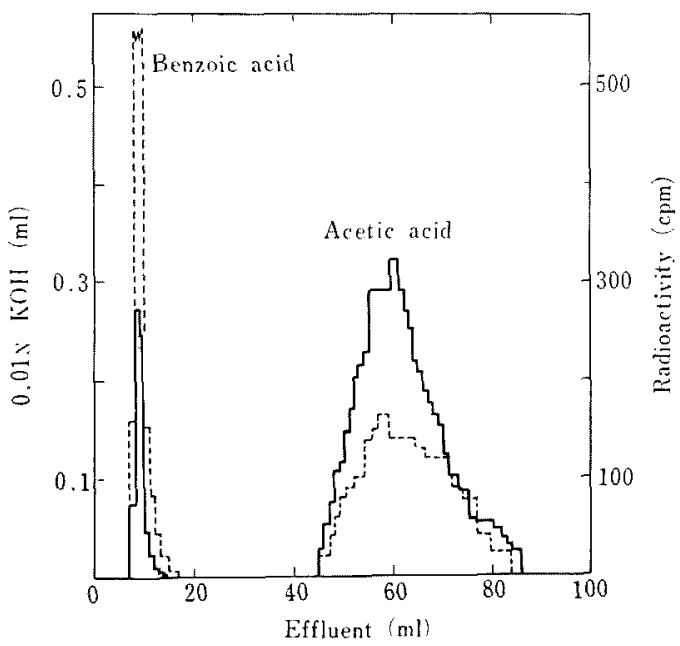

FIG. 1. Chromatogram of the Products of Toluenemethyl $14 \mathrm{C}$ Degradation by the Crude Extracts of P. mildenbergii.

The ether extracts obtained from six identical reaction mixtures as described in the text were rombined, and evaporated to dryness with a small amount of alkali. The residue was taken up in $10 \% \mathrm{H}_{2} \mathrm{SO}_{4}$, adjusted to $\mathrm{pH}$ less than 2, mixed with a known amount of organic acids, then submitted to chromatography on Celite column. The system was $0.2 \mathrm{~N} \mathrm{~N}_{2} \mathrm{SO}_{4}$ on Celite 535 , developed with chloroform. Solid line: radioactivity curve, dotted line: titration curve.

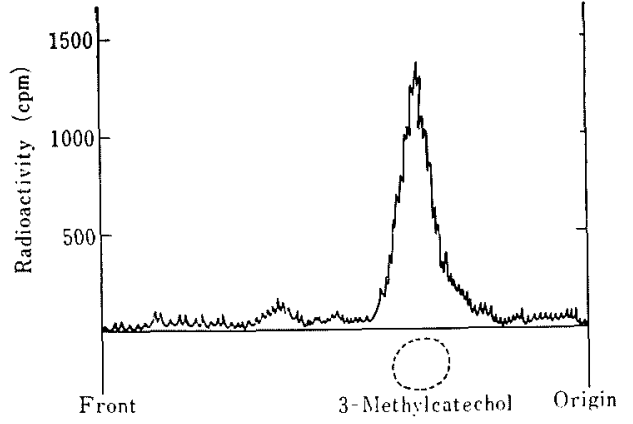

FIG. 2. Thin-layer Chromatogram of the Products of Toluene-methyl-14 $\mathrm{C}$ Degradation after the Incubation with Non-labelled 3-Methylcatechol.

After the incubation was carried out in the presence of $5 \mu$ moles of 3-methylcatechol, the ether extracts of the reaction products were evaporated, and the residue was taken up in a small amount of ether, then applied to a thin-layer plate of silica gel, which was subsequently developed with hexaneether-formic acid $(180: 20: 5, \mathrm{v} / \mathrm{v} / \mathrm{v})$. The radioactivity was determined by a thin-layer chromatogram scanner (Nihon-Musen Co.). The major radioactive peak migrated with carrier 3-methylcatechol. Identification of 3-methylcatechol as the product was further performed using paper chromatography with the solvent system of $\mathrm{CCl}_{4}$-butanol $(20: 1, \mathrm{v} / \mathrm{v}){ }^{4}$ ) The radioactivity was measured with a windowless paper chromatogram scanner.

ether extracts of the reaction products also revealed the formation of benzoic acid as a minor reaction product. No labelled 3-methylcatechol was detected as the reaction product. However, when non-labelled 3-methylcatechol was added in the reaction mixture during the incubation, labelled 3-methylcatechol was found to accumulate (Fig. 2). These results suggest that the degradation of toluenemethyl $-{ }^{14} \mathrm{C}$ in this crude extracts is mainly initiated by the hydroxylation of benzene ring, giving 3-methylcatechol, which in turn undergoes the ring-fission and provides labelled acetic acid, and that the conversion of toluene to benzoic acid is only the minor pathway of toluene degradation.

In order to determine the conversion of toluene to acetic acid routinely, the ether 
extract containing the reaction products was applied to an alumina column. After toluene was completely removed from the column with petroleum ether, the labelled reaction products mainly consisting of acetic acid was eluted with acetic acid-methanol $(1: 3, \mathrm{v} / \mathrm{v})$,

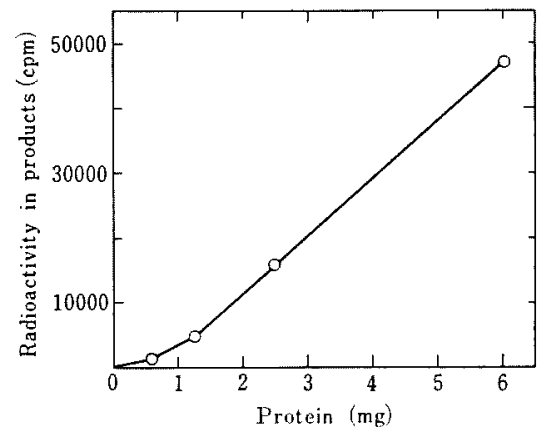

FIG. 3. Dependence of Toluene-methyl-14 C Degradation on the Concentration of the Crude Extracts.

The reaction condition was the same as in the text.

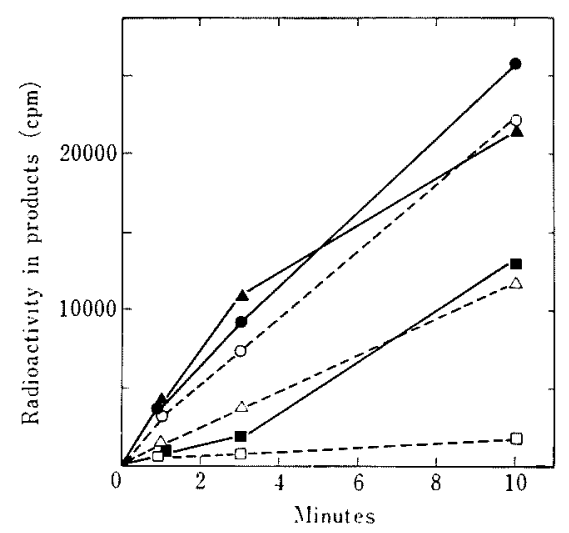

FIG. 4. Pyridine Nucleotide Requirement for the Degradation of Toluene-methyl-14 $\mathrm{C}$ by the Crude Extracts before and after Charcoal Treatment.

Twenty $\mathrm{ml}$ of crude extracts ( $12 \mathrm{mg}$ of proteins) was stirred with $480 \mathrm{mg}$ of Norite $A$ for $20 \mathrm{~min}$ at $0^{\circ} \mathrm{C}$, followed by centrifugation. Untreated crude extracts, $-\square$ no pyridine nucleotide; $\mathbf{A}-\boldsymbol{\Delta}$ NADH $(0.25 \mu$ mole $) ;-\mathrm{NADPH}(0.25 \mu$ mole $)$. Charcoal-treated crude extracts, $\square-\square$ no pyridine nucleotide; $\triangle \cdots \triangle \mathrm{NADH}(0.25 \mu$ mole $) ; \mathrm{O}-\mathrm{O}$ NADPH $(0.25 \mu \mathrm{mole})$. in a similar way as described before." The radioactivity of the eluate was determined with a liquid scintillation spectrometer. Figure 3 shows the dependence of labelled acetic acid formation from toluene-methyl $1{ }^{14} \mathrm{C}$ on the concentration of the crude extracts. When the crude extracts were treated with charcoal, it was revealed that pyridine nucleotide was involved as a cofactor in the reaction. As indicated in Fig. 4, treatment of the crude extracts with charcoal resulted in great loss of the activity. Addition of NADPH completely restored the activity. NADP was slightly less effective than NADPH. NADH or NAD exhibited similar effect. Dialysis against $1 \mathrm{~mm}$ o-phenanthroline-containing Tris- $\mathrm{HCl}$ buffer also remarkably decreased the activity, and the addition of NADPH and ferrous ion resulted in the almost complete restoration of the activity. Addition of ferrous ion alone had no effect. o-Phenanthroline at $1 \mathrm{~mm}$ or EDTA at $0.1 \mathrm{~mm}$ showed approximately $50 \%$ inhibition. Tiron at $1 \mathrm{~mm}$ had slight stimulation effect. In a few instances, two distinct protein fractions separated with $0.45 \sim 0.6$ and $0.6 \sim 0.9$ saturation of ammonium sulfate from the crude extracts showed a combined effect for the maximal activity of toluene degradation. $P$. denitrificans rubredoxin ${ }^{6}$ or spinach ferredoxin did not replace either. In no case, FAD or FMN had appreciable effect, in contrast to the xylene hydroxylation system of $P$. aeruginosa. ${ }^{11}$

While this work was in progress, Gibson et al. ${ }^{\text {" }}$ reported the mechanism of the early stage of benzene degradation by Pseudomonas putida. Although our organism did not grow so well on benzene as a sole carbon source, it seems probable that the mechanism for the first step of toluene degradation in this organism may be similar to that of benzene oxygenation by P. putida. ${ }^{71}$

6) M. Kusunose, J. Matsumoto, K. Ichihara, E. Kusunose and J. Nozaka, $J$. Biochem., 61, 665 (1967).

7) D. T. Gibson, J. R. Koch and R. E. Kallio, Biochemistry, 7, 2653 (1968). 